\title{
PENGARUH PERGAULAN TERHADAP KENAKALAN “ABG” DI YOGYAKARTA MENGGUNAKAN REGRESI LOGISTIK
}

\author{
Ridayati \\ Dosen Matematika pada Teknik Sipil STTNas \\ Sekolah Tinggi Teknologi Nasional \\ Jalan Babarsari, Caturtunggal, Depok, Sleman, Yogyakarta \\ ridayati@gmail.com
}

\begin{abstract}
Junior and Senior High School is the period for what we called unstable of "Anak Baru Gede (ABG)". Application of high technology like internet, is the ordinary things for students of Junior and Senior High School in Yogyakarta, which is used for doing their homework. Nevertheless, high tech is used for looking friends through Facebook, Twitter, etc as well. Nowadays, ABG are always curious of the new things, that lead them to inappropriate research. Even more, lack of parents concern is impacted to immoral behavior. Besides, negative environment gives the fundamental factor to immoral behavior as well. Hence, it effected to mentally and morally degradation.

The objective of this research is for identifying the role of society to $A B G$ 's mischievousness in Yogyakarta. This research is used qualitative approach with case study's methodology to obtain data and description related to $A B G$ 's mischievousness in Yogyakarta. Next, is using Logistic Regression analysis to analyze the connection. The result is $Y=4.745-$ $1.054 X$ equation. Hence, it concluded that increased one unit of society's role will decrease the degree of $A B G$ 's mischievousness by 1.054.
\end{abstract}

Keywords: society, $A B G$, moral, multiple logistic regression

Abstrak

Masa-masa SMP dan SMA adalah masa "Anak Baru Gede (ABG)" yang masih labil. Penggunaan teknologi yang canggih seperti internet merupakan hal yang tidak asing lagi bagi pelajar-pelajar SMP dan SMA di Yogyakarta. Para pelajar biasa menggunakannya untuk tugas sekolahnya. Namun, Hal ini juga dimanfaatkan untuk mencari banyak teman melalui Facebook, Twitter, dan lain-lain. Pada masa ini ABG selalu ingin tau hal-hal yang baru, sehingga ada kemungkinan pula para $\mathrm{ABG}$ mengakses hal-hal yang belum semestinya melalui internet. Kurangnya perhatian orang tua akan mengakibatkan Teknologi canggih berakibat pada moral yang jelek. Selain itu, Pergaulan yang negatif adalah salah satu dari sekian banyak penyebab kehancuran moral ABG. Hal ini berakibat pada mental dan moral yang lemah.

Penelitian ini bertujuan untuk mengidentifikasi peran pergaulan terhadap kenakalan ABG di DIY. Penelitian ini menggunakan pendekatan kualitatif dengan metode studi kasus untuk mendapatkan data dan gambaran mengenai kenakalan ABG di DIY. Selanjutnya digunakan Analisis Regresi Logistik untuk mengetahui keterkaitannya. Hasil analisis 
diperoleh persamaan $\mathrm{Y}=4,745-1,054 \mathrm{X}$. Hal ini berarti bahwa peran pergaulan yang naik satu satuan akan menurunkan tingkat kenakalan ABG sebesar 1,054.

Kata kunci: Pergaulan, ABG, moral, regresi logistik ganda

\section{Pendahuluan}

Masa Anak Baru Gede (ABG) adalah masa yang paling rawan. Mario Teguh dalam MTGW mengatakan bahwa 'Sebagian besar masalah ABG adalah kebiasaan buruk yang dibiarkan menguat oleh orang tua yang tidak sempat memperhatikan, yang tidak tahu bahwa itu harus dicegah, atau yang tidak perduli'. Dalam era modernisasi sekarang ini berkenaan dengan perkembangan kecanggihan teknologi, peran penting orang tua sangat dibutuhkan. Sesuatu yang tidak dapat dihindari bahwa teknologi berkembang dengan pesat sehingga penggunaannya sering disalahgunakan. Teknologi Informasi yang paling sering digunakan ABG adalah akses internet yang mudah ditemui. Meskipun pemerintah sudah mengeluarkan undang-undang anti pornoaksi dan pornografi namun tetap saja para ABG sering mengakses konten yang dapat merusak moral sang remaja. Selain Teknologi yang canggih, Pergaulan yang negatif adalah salah satu dari sekian banyak penyebab kehancuran moral ABG. Permasalahan yang lain adalah narkoba. Narkoba menjadi jurang kehancuran bagi ABG.

Yogyakarta merupakan kota pelajar yang tidak terlepas dari kecanggihan teknologi Informasi. Pelajar-pelajar di sekolah SMP bahkan SD sudah menggunakan teknologi ini untuk tugas sekolahnya. Besar kemungkinan para pelajar ini juga mengakses konten yang belum semestinya. Kurangnya perhatian orang tua akan mengakibatkan Teknologi canggih yang semestinya diciptakan untuk menambah wawasan malah berakibat pada moral yang jelek. Bahkan banyak lulusan sarjana berotak cerdas dalam menjawab soal ujian, namun mental dan moralnya lemah.

Berangkat dari latar belakang diatas, terkait dengan isu yang berkembang tentang kenakalan ABG di DIY penulis tertarik mengkaji peran pergaulan ABG di DIY. Penulis beranggapan bahwa menjadi orang tua bukan soal siapa, tetapi apa yang dilakukan. Pengasuhan tidak hanya mencakup tindakan tetapi mencakup pula apa yang dikehendaki agar anak mengerti akan hidup, apa artinya hidup, dan bagaimana menjalani kehidupan ini dengan baik.

\section{Tinjauan Pustaka}

Mengasuh dan membesarkan anak membutuhkan pengetahuan dan ketrampilan yang berbeda dibanding anak balita (Faried, 2009). Hal ini dikarenakan anak menjelang ABG terus mengalami perubahan dan perkembangan secara cepat. Selain perubahan fisik yang tumbuh menjadi besar dan tinggi, kemampuan psikis, sikap dan perilakunya pun berubah. Tingkah lakunya menjadi sulit dimengerti bahkan seringkali membantah atau menyanggah pendapat yang diberikan. Saat itu mereka sedang menjelma menjadi dewasa. Jika ABG tersebut berperilaku sesuai dengan kaidah moral maka $A B G$ tersebut berkarakter mulia. Dalam penelitian ini, hal penting yang menjadi dasar analisis adalah pendidikan karakter, kenakalan $\mathrm{ABG}$, serta regresi logistik untuk analisnya.

\subsection{Pendidikan Karakter dan kenakalan ABG}

UU No 20 tahun 2003 Tentang Sistem Pendidikan Nasional pasal 3 menyebutkan bahwa pendidikan nasional berfungsi mengembangkan kemampuan dan membentuk karakter serta peradaban bangsa yang bermartabat dalam rangka mencerdaskan kehidupan bangsa. 
Menurut Elkind dan Sweet (Kemendiknas 2010), pendidikan karakter dimaknai sebagai berikut :

"character education is the deliberate effort to help people understand, care about, and act upon core ethical values. When we think about the kind of character we want for our children, it is clear that we want them to be able to judge what is right, caredeeply about what is right, and then do what they believe to be right, even in the face of pressure from without and temptation from within".

Menurut T. Ramli dalam Aswani (2003), pendidikan karakter memiliki esensi dan makna yang sama dengan pendidikan moral dan pendidikan akhlak. Sementara itu, menurut Buchori (Muslich, 2011), pendidikan karakter seharusnya membawa peserta didik ke pengenalan nilai secara kognitif, penghayatan nilai secara afektif, dan akhirnya ke pengamalan nilai secara nyata.

Pada dasarnya kenakalan ABG menunjuk pada suatu bentuk perilaku ABG yang tidak sesuai dengan norma-norma yang hidup di dalam masyarakatnya. Kartini Kartono (1988) mengatakan $\mathrm{ABG}$ yang nakal itu disebut pula sebagai anak cacat sosial. Mereka menderita cacat mental disebabkan oleh pengaruh sosial yang ada ditengah masyarakat, sehingga perilaku mereka dinilai oleh masyarakat sebagai suatu kelainan dan disebut "kenakalan". Tentang normal tidaknya perilaku kenakalan atau perilaku menyimpang, pernah dijelaskan dalam pemikiran Emile Durkheim (dalam Soerjono Soekanto, 1985). Bahwa perilaku menyimpang atau jahat kalau dalam batas-batas tertentu dianggap sebagai fakta sosial yang normal dalam bukunya Rules of Sociological Method dalam batas-batas tertentu kenakalan adalah normal karena tidak mungkin menghapusnya secara tuntas, dengan demikian perilaku dikatakan normal sejauh perilaku tersebut tidak menimbulkan keresahan dalam masyarakat, perilaku tersebut terjadi dalam batas-batas tertentu dan melihat pada sesuatu perbuatan yang tidak disengaja. Jadi kebalikan dari perilaku yang dianggap normal yaitu perilaku nakal/jahat yaitu perilaku yang disengaja meninggalkan keresahan pada masyarakat.

\subsection{Analisis Regresi Logistik}

Model regresi secara umum dapat dinyatakan secara matematis sebagai Persamaan 1 (Pamungkas, 2007):

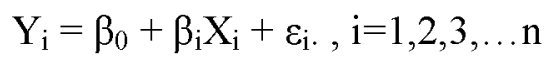

dengan :

$\mathrm{Y}_{\mathrm{i}} \quad$ : nilai variabel dependent pada observasi ke-i

$\beta_{0}$ dan $\beta_{\mathrm{i}} \quad$ : parameter koefisien regresi

$\mathrm{X}_{\mathrm{i}} \quad$ : konstanta yang diketahui yaitu nilai variabel independent pada observasi ke-i

$\varepsilon_{\mathrm{i}}$ error yang bersifat random, $\varepsilon_{\mathrm{i}} \sim \mathrm{N}\left(0, \sigma^{2}\right)$ yang tidak saling berkorelasi.

Analisis regresi logistik (biner) yang sering disebut regresi logistik adalah analisis regresi dimana variabel respon hanya memiliki dua kemungkinan nilai (dikotomous), misalnya ya atau tidak, sukses atau gagal, sehat atau sakit, dan lain sebagainya (Utami, 2007) Regresi logistik merupakan salah satu solusi yang dapat digunakan untuk menganalisis kasuskasus penelitian, dengan tujuan untuk mencari pola hubungan antara sekumpulan variabel prediktor dengan suatu variabel respon bertipe kategorik atau kualitatif secara simultan. Tujuan utama dari analisis regresi logistik adalah memprediksi probabilitas terjadinya atau tidak terjadinya event (terjadinya non event) berdasarkan nilai-nilai prediktor yang ada, mengklasifikasikan subyek penelitian berdasarkan ambang (threshold) probabilitas. Event 
merupakan status atau peristiwa dari variabel respon yang menjadi pokok perhatian (diberi nilai kode yang lebih tinggi daripada non event), misalnya kategori "nakal" menjadi event (diberi kode 1) sedangkan "tidak nakal" menjadi non event (diberi kode 0 ).

\section{Metode Penelitian}

Metode penelitian yang dipakai adalah deskriptif evaluatif, yaitu metode penelitian yang mengevaluasi kondisi objektif/ apa adanya pada suatu keadaan yang menjadi obyek studi (Supriharyono, 2002). Obyek studi yang dimaksud adalah para ABG yaitu pelajar SMA dan SMP di DIY sebanyak 200 responden. Data diperoleh melalui kunjungan ke sekolahsekolah, namun sebagian data diperoleh melalui facebook maupun twitter remaja-remaja yang sering mengupdate status tentang "cinta" dan "galau". Sebanyak 200 responden yang tercatat dengan beberapa variabel. Penelitian ini memberikan gambaran tentang keadaan atau fenomena secara sistematis dan akurat mengenai fakta-fakta pada saat penelitian dilakukan (masalah-masalah yang bersifat aktual). Selanjutnya dari 200 data responden tersebut diatas, data diolah menggunakan Statistik Inferensial berupa Regresi Logistik untuk mengetahui pengaruh pergaulan terhadap kenakalan ABG di Yogyakarta.

\section{Hasil Yang Dicapai}

Masa ABG merupakan masa yang penuh problema. Dalam masa ini tidak sedikit ABG yang mengalami kegoncangan yang menyebabkan munculnya emosional yang belum stabil sehingga mudah melakukan pelanggaran terhadap norma-norma dalam aturan sekolah dan masyarakat. ABG sebagai manusia yang sedang tumbuh dan berkembang terus melakukan interaksi sosial baik antara sesama ABG maupun terhadap lingkungan lain. Melalui proses adaptasi, ABG mendapatkan pengakuan sebagai anggota kelompok baru yang ada dalam lingkungan sekitarnya. ABG rela menganut kebiasaan-kebiasaan yang berlaku dalam suatu kelompok ABG.

Menurut media Center PSKK UGM, Perubahan komposisi penduduk menurut umur membawa implikasi yang lain terutama peningkatan jumlah penduduk usia ABG. Persentase remaja DIY akan mencapai 24,13 persen dengan pertumbuhan tiga kali lipat (3,24 persen) dibandingkan dengan pertumbuhan penduduk. Jumlah remaja di DIY meningkat karena dampak dari meningkatnya pula derajat kesehatan penduduk sehingga angka kematian bayi dan anak pun menurun. Selain itu perubahan jumlah penduduk remaja DIY juga tidak bisa dilepaskan dari migrasi masuk ke DIY.

Berikut adalah hasil kuesioner dan wawancara dengan responden, dalam hal ini anakanak SMP dan SMA tentang faktor-faktor yang mempengaruhi kenakalan ABG di DIY dan peran keluarga dalam membentuk karakter ABG serta pengaruh-pengaruhnya.

\subsection{Faktor-Faktor yang mempengaruhi kenakalan ABG di DIY}

Pergaulan ABG di DIY pada zaman sekarang ini sudah sampai pada taraf mengkhawatirkan. Semua media massa baik elektronik maupun cetak dengan leluasa menampilkan hal-hal yang dapat mengakibatkan kerusakan akhlak generasi muda, mudah mencari teman sebaya. Ternyata faktor teman sangat berpengaruh dalam pembentukan kepribadiannya. Beberapa ABG mengaku bahwa Justru mereka cenderung lebih terbuka kepada teman sebayanya daripada kepada orangtuanya karena mereka lebih banyak menghabiskan waktu bersama teman.

Ketua Pengurus Daerah Perkumpulan Keluarga Berencana Indonesia (PKBI) DIY memaparkan tentang persoalan yang dihadapi remaja khususnya di Yogyakarta. Pada usia 
remaja biasanya terjadi peningkatan terhadap dorongan seks. Bahkan, tidak sedikit pula para remaja yang berperilaku seks aktif (sexually active). Remaja yang secara seksual adalah aktif, namun situasi tidak diimbangi dengan pengetahuan atau informasi seksualitas yang memadai. Banyak orang berpandangan, pendidikan seks itu sama seperti mengajari orang untuk berhubungan seksual. Padahal tidaklah sesempit itu.

Sebenarnya banyak sekali faktor yang menyebabkan kenakalan ABG pada umumnya, sehingga dapat dikatakan bahwa faktor penyebab yang sesungguhnya belum diketahui dengan pasti. Melakukan intervensi pendidikan terhadap ABG dizaman modern sekarang ini jauh lebih sukar dibandingkan dengan zaman dahulu, ini disebabkan situasi kehidupan dewasa ini sudah semakin kompleks. Pengaruh kompeksitas kehidupan dewasa ini sudah tampak pada berbagai fenomena yang perlu memperolah perhatian pendidikan. Beberapa fenomena bentuk kompleksitas permasalahan kenakalan ABG yang berpotensi menimbulkan kejahatan yang dilakukan oleh ABG di DIY adalah perkelahian pelajar antar sekolah, Merokok, minum-minuman keras, alkohol, pelecehan sexsual, mengakses film porno. Apalagi sekarang dianggapnya wajar bila remaja sudah memiliki pacar. Meningkatnya kasus kekerasan antar pelajar saat ini di DIY sudah sangat mengkhawatirkan apalagi jika ada pelajar yang membawa senjata tajam hanya untuk tawuran.

Penulis bertanya kepada salah seorang responden di suatu SMA di DIY "Alasan apa yang membuat responden ikut-ikutan tawuran?" Responden menjawab "solidaritas", dan bahkan jika ada teman yang mengajak merokok, minum-minuman keras, itu juga solidaritas. Sekarang jika diperhatikan bahwa sikap solidaritas itu sudah beralih fungsi yaitu solidaritas yang dulunya berarti positif seperti misalnya membantu teman yang tertinggal pelajarannya dengan meminjamkan catatan, atau membantu teman untuk menyelesaikan masalahmasalahnya, kini disalahartikan menjadi bekerjasama yang bersifat negatif.

Responden yang lain menceritakan bagaimana pengalamannya memakai jilbab karena pengaruh dari teman-temannya. Responden mengaku bahwa Teman-teman dikelasnya itu pengetahuan agamanya lebih dalam, kemudian mereka sering membahas masalah-masalah kehidupan bersama-sama sebagai selingan kejenuhan mengerjakan tugas sekolah, mereka tidak takut dikatakan pilih-pilih teman karena mereka mempunyai prinsip. Mencari teman yang baik, supaya ketularan menjadi ABG yang baik pula.

Ini berarti bahwa positif dan negatif teman sebaya akan berpengaruh pada pembentukan identitas ABG tersebut. Misalnya, ABG yang cenderung bergaul dengan teman-teman sebayanya yang sering mabuk-mabukan dan menggunakan narkoba akan sangat rentan untuk mengikuti gaya hidup mereka. Meskipun belum dinyatakan mutlak bahwa ABG tersebut akan mengikuti gaya hidup teman-temannya namun perlu disadari bahwa masa $A B G$ merupakan ketidakstabilan, baik dalam pemikiran dan pemegangan prinsip hidup. Apalagi dengan rasa keingintauan (eksplorasi) yang besar dan ingin mendapatkan pengakuan dari teman-teman sebaya. Kelompok teman sebaya diakui dapat mempengaruhi pertimbangan dan keputusan seorang remaja tentang perilakunya.

\subsection{Pengaruh pergaulan terhadap kenakalan ABG menggunakan Analisis Regresi Logistik.}

\subsubsection{Karakteristik Responden}

Karakteristik responden yang diamati dalam penelitian ini berdasarkan jenis kelamin, usia, dan pendidikan. 
Responden yang berusia dibawah 17 tahun sebanyak 101 orang (50,5\%). Usia dibawah 17 tahun yang dimaksud adalah usia anak-anak SMP di Yogyakarta yaitu antara 12 tahun sampai 16 tahun. Sedangkan responden yang berusia sama atau diatas 17 tahun sebanyak 99 orang $(49,5 \%)$. Usia ini adalah usia anak-anak remaja SMA di Yogyakarta yaitu antara 17 tahun sampai 19 tahun.

Karakteristik Responden berjenis kelamin laki-laki sebanyak 100 orang $(50,0 \%)$ dan responden perempuan sebanyak 100 orang $(50,0 \%)$. Hal ini sengaja penulis pilih agar bisa dianalisis secara sebanding antara remaja putri dan remaja putra.

Karakteristik Responden SMA sebanyak 100 orang $(50,0 \%)$ dan responden SMP sebanyak 100 orang $(50,0 \%)$. Hal ini sengaja penulis pilih agar bisa dianalisis secara sebanding antara remaja SMA dan remaja SMP.

\subsubsection{Deskripsi Data}

Data yang digunakan untuk analisis yaitu data anak-anak SMP dan SMA yang berada di Yogyakarta dengan cara mendatangi sekolahan-sekolahan di 5 kabupaten di Yogyakarta dan sebagian juga melalui facebook maupun twitter. Penulis mencari remaja-remaja yang sering mengupdate status tentang "cinta" dan "galau". Sebanyak 200 responden yang tercatat dengan beberapa variabel. Variabel Pergaulan menunjukkan pergaulan ABG dengan teman sebayanya, Perilaku teman dekatnya. Variabel ini merupakan variabel prediktor yang bertipe independent yang merupakan data kuantitatif. Variabel Kenakalan ABG menunjukkan tentang seseorang yang diduga nakal apakah seseorang tersebut sebelumnya mempunyai riwayat kurang perhatian orangtuanya atau tidak. Variabel ini merupakan variabel respon yang bertipe kategorik dengan kode 1 untuk nakal dan kode 0 untuk tidak nakal. Data penelitian variabel kenakalan dan pergaulan remaja diperoleh melalui jumlah butir jawaban kuesioner yang telah diujikan validitas dan reliabilitas.

Responden dalam kategori "nakal" sebanyak 119 orang $(59,5 \%)$ dan responden dalam kategori "tidak nakal" sebanyak 81 orang $(40,5 \%)$. Data kenakalan remaja adalah berkelahi, mengkonsumsi alcohol, mengakses film porno, berciuman dengan pacar, melakukan hubungan sex, senang berpacaran, merasa malu jika tidak mengikuti teman-temannya, lebih sering "curhat" dengan temannya daripada sama orangtuanya. Pada analisis ini, remaja dikatakan "nakal" jika mempunyai nilai $<4$ dan dikatakan "tidak nakal" jika mempunyai nilai $>=4$.

Deskripsi responden berdasarkan pergaulan. Responden dalam kategori "berteman dengan ABG yang nakal" sebanyak 7 orang $(3,5 \%)$ dan responden dalam kategori "berteman dengan ABG yang biasa-biasa saja" sebanyak 136 orang $(68,0 \%)$ dan responden dalam kategori "berteman dengan ABG yang baik" sebanyak 57 orang $(28,5 \%)$. Data pergaulan, diantaranya adalah teman dekat yang suka berkelahi, teman dekat yang sering mengkonsumsi alkohol, teman dekat yang sering mengakses film porno di internet, teman dekat yang selalu mempengaruhi teman-temannya untuk berbuat tidak baik, teman yang suka berpacaran, teman yang pernah berhubungan sex dengan lawan jenisnya, teman yang lebih senang "curhat" kepada teman daripada orangtuanya sendiri?

Pada analisis ini, pergaulan dikatakan "kurang" jika mempunyai nilai $<2,33$ dan dikatakan "cukup" jika mempunyai nilai antara 2,33 sampai dengan 4,67 dan dikatakan "baik" jika mempunyai nilai $>=4,67$. 


\subsubsection{Pengaruh Pergaulan terhadap kenakalan remaja}

Peran keluarga sangat besar pengaruhnya terhadap kenakalan remaja. Hal ini ditunjukkan dalam Tabel 1 .

Tabel 1 menunjukkan deskripsi responden berdasarkan hubungan pergaulan remaja terhadap kenakalan remaja. Dari 7 responden $(3,5 \%)$ yang berteman dengan remaja yang "nakal", semua responden tersebut ikut menjadi anak "nakal". Dari 136 Responden $(68,0 \%)$ yang berteman dengan anak yang biasa-biasa saja terdapat 92 responden (46\%) masuk kategori "nakal" dan 44 responden (22\%) masuk kategori "tidak nakal". Dari 57 Responden $(28,5 \%)$ yang berteman dengan remaja yang baik-baik terdapat 20 responden $(10 \%)$ masuk kategori "nakal" dan 37 responden $(18,5 \%)$ masuk kategori "tidak nakal". Dari data tersebut terlihat bahwa remaja yang berteman dengan teman yang baik-baik pun juga ada yang "nakal". Apalagi remaja yang berteman dengan remaja yang "nakal" maka remaja tersebut cenderung ikut"nakal". Tabel 9 menunjukkan peran keluarga yang berpengaruh signifikan terhadap kenakalan remaja dengan nilai sig $0,000<0,05$.

Tabel 1. Tabulasi Silang pergaulan dengan kenakalan remaja di DIY

\section{Crosstab}

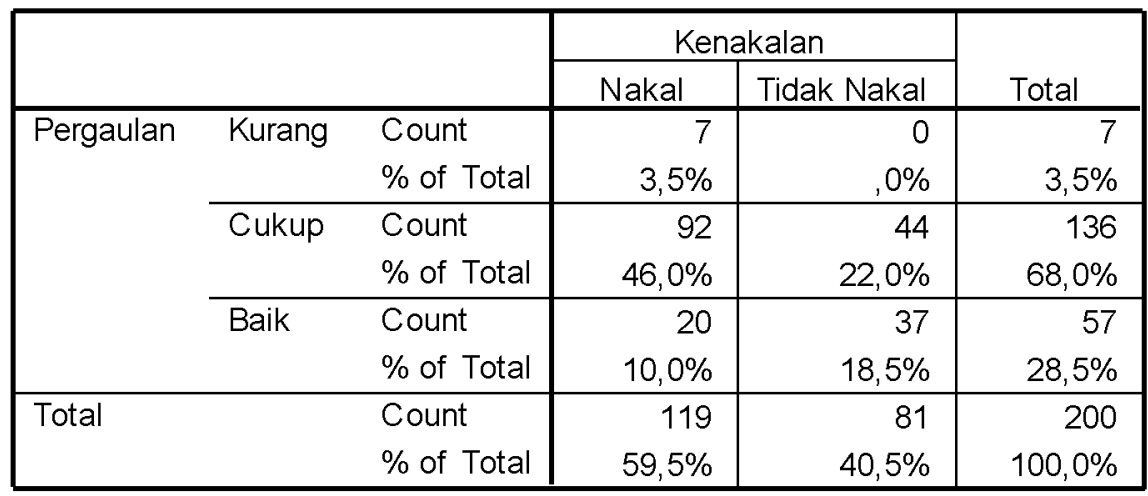

\subsubsection{Regresi Logistik}

Pemodelan pada regresi logistik secara umum tidak jauh berbeda dengan regresi linear. Data dalam kasus ini diolah dengan metode regresi logistik ganda menggunakan paket program SPSS 15 untuk mengetahui faktor-faktor resiko yang berpengaruh signifikan terhadap status seseorang yang positif nakal. Berikut adalah hasil verifikasi variable predictor. Langkah ini bertujuan untuk melihat kemampuan atau kontribusi setiap variable Prediktor dalam menjelaskan variable respon. Statistik uji yang digunakan adalah $p$-value. Berikut ini adalah verifikasi variable pergaulan ABG yang ditunjukkan dalam Tabel 2.

Tabel 2. Verifikasi Univariat Variabel Pergaulan

Variables in the Equation

\begin{tabular}{|c|c|c|c|c|c|c|c|}
\hline & $\mathrm{B}$ & S.E. & Wald & df & Sig. & $\operatorname{Exp}(B)$ \\
\hline Step & Pergaulan & $-1,054$ & .228 & 21,388 & 1 &, 000 &, 349 \\
\hline 1 & Constant & 4,745 & 971 & 23,900 & 1 &, 000 & 114,991 \\
\hline
\end{tabular}

a. Variable(s) entered on step 1: Pergaulan. 
Uji hipotesis yang digunakan adalah :

$\rightarrow \mathrm{H}_{0}$ : peran pergaulan tidak berpengaruh signifikan terhadap kenakalan $\mathrm{ABG}$.

$\mathrm{H}_{1}$ : peran pergaulan berpengaruh signifikan terhadap kenakalan ABG.

$\rightarrow$ Tingkat signifikansi : $\alpha=0.05$

$\rightarrow$ Statistik uji : $p$-value

$\rightarrow$ Daerah kritis : $\mathrm{H}_{0}$ ditolak bila $p$-value $<\alpha$

Sedangkan pada baris pergaulan, Sig menunjukkan $0,000<0,05$ yang berarti menolak Ho yaitu variabel pergaulan sangat berpengaruh signifikan terhadap kenakalan ABG di DIY. Persamaan regresi yang diperoleh adalah y $=4,745-1,054 \mathrm{x}$. Hal ini berarti bahwa pergaulan yang naik satu satuan akan menurunkan tingkat kenakalan ABG sebesar 0,129.

\section{Kesimpulan dan Saran}

\subsection{Kesimpulan}

Perkembangan kepribadian dan perilaku anak, sangat ditentukan oleh bagaimana orang tua mendidiknya, pergaulan, lingkungan yang kemudian akan menjadi kebiasaan. Pada kenyataannya banyak faktor yang menyebabkan kenakalan $A B G$ pada umumnya sehingga dapat dikatakan bahwa faktor penyebab yang sesungguhnya belum diketahui dengan pasti.

Perubahan komposisi penduduk menurut umur membawa implikasi yang lain terutama peningkatan jumlah penduduk usia ABG. Persentase remaja DIY akan mencapai 24,13 persen dengan pertumbuhan tiga kali lipat (3,24 persen) dibandingkan dengan pertumbuhan penduduk. Beberapa fenomena bentuk kompleksitas permasalahan kenakalan ABG yang berpotensi menimbulkan kejahatan yang dilakukan oleh ABG di DIY adalah perkelahian pelajar antar sekolah, Merokok, minum-minuman keras, alkohol, pelecehan sexsual, mengakses film porno.

Analisis Pengaruh Pergaulan terhadap kenakalan ABG menggunakan Analisis Regresi Logistik diperoleh persamaan $\mathrm{y}=4,745-1,054 \mathrm{x}$. Hal ini berarti bahwa peran pergaulan yang naik satu satuan akan menurunkan tingkat kenakalan ABG sebesar 1,054. Contohnya untuk pergaulan yang bernilai 2 , maka nilai kenakalan remaja adalah $4,745-1,054(2)=$ 2,637 . Nilai sig yang kurang dari 0,05 menunjukkan bahwa variable prediktor berpengaruh signifikan terhadap kenakalan ABG di DIY.

\subsection{Saran}

Orang tua seharusnya aktif mendampingi anaknya, mempunyai waktu khusus untuk anaknya. Bisa menjadi 'teman' terlebih bila anak-anak nya sedang dalam masalah. 


\section{Daftar Pustaka}

Agresti, A, 1990, Categorical Data Analysis. New York : John Wiley \& Sons.

Asmani, Jamal Ma'mur, 2012, Kiat Mengatasi Kenakalan ABG di Sekolah, Buku Biru, Wonokerto.

Faried, 2009, Delapan Kompetensi Dasar Mengajar. [Online]

Hosmer, D. dan Stanley Lemeshow, 1989, Applied Logistic Regression. New York : John Wiley \& Sons.

Idris, Zahara dan Jamal, Lisma, 1992, Pengantar Pendidikan 2, PT Grasindo, Jakarta.

Kartini Kartono, 1988, Psikologi ABG, PT.Rosda Karya, Bandung.

Kemendiknas, 2010, Pembinaan Pendidikan Karakter di Sekolah Menengah Pertama, Jakarta

Muslich, M, 2011, Pendidikan Karakter, Bumi Aksara, Jakarta

Pamungkas, H, 2007, Aplikasi Model Regresi Logistik Ganda Pada Data Kesehatan Di Balai Laboratorium Kesehatan Dinas Kesehatan Provinsi DIY. Jogjakarta : Program Studi Statistika FMIPA UGM

Soekanto, Soerjono, 1985 max Weber, Konsep-konsep dasar dalam sosiologi. CV Rajawali, Jakarta.

Supriharyono, 2002, Intisari Materi Kuliah Metodologi Penelitian, Program Pasca Sarjana Magister Teknik Sipil Universitas Diponegoro, Semarang.

Utami, R. 2007, Pemodelan Faktor-Faktor Resiko Terjadinya Gangguan Telepon Rumah (PSTN) Di Wilayah Jogjakarta Menggunakan Analisis Regresi Logistik Ganda, Jogjakarta: Program Studi Statistika FMIPA UGM

Zulaela, 2007, Modul Praktikum Analisa Data Kategorik, Jogjakarta: Laboratorium Komputasi Program Studi Statistika FMIPA UGM. 
Ridayati 